\title{
Article
}

\section{Psycho-behaviourally based features of effective talent development in Rugby Union: A coach's perspective}

Hill, A., MacNamara, Á., and Collins, D.

Available at http://clok.uclan.ac.uk/12094/

Hill, A., MaCNamara, Á., ORCID: 0000-0002-8110-6784 and Collins, D. ORCID: 0000-0002-7601-0454 (2015) Psycho-behaviourally based features of effective talent development in Rugby Union: A coach's perspective. The Sport Psychologist, 29 (3). pp. 201-212. ISSN 0888-4781

It is advisable to refer to the publisher's version if you intend to cite from the work. http://dx.doi.org/10.1123/tsp.2014-0103

For more information about UCLan's research in this area go to http://www.uclan.ac.uk/researchgroups/ and search for <name of research Group>.

For information about Research generally at UCLan please go to http://www.uclan.ac.uk/research/

All outputs in CLoK are protected by Intellectual Property Rights law, including Copyright law. Copyright, IPR and Moral Rights for the works on this site are retained by the individual authors and/or other copyright owners. Terms and conditions for use of this material are defined in the policies page. 
1 This is a pre-proof corrected manuscript as accepted for publication on 26 January 2015, of 2 an article published by Human Kinetics in The Sport Psychologist, available online:

3 http://dx.doi.org/10.1123/tsp.2014-0103

4 PLEASE REFER TO THE PUBLISHED VERSION FOR CITING PURPOSES 5

Psycho-behaviourally Based Features of Effective Talent Development in Rugby Union:

A Coach's Perspective

21 Corresponding Author: Andy Hill, Institute of Coaching and Performance, University of

22 Central Lancashire, Preston, UK, PR1 2HE. AHill@uclan.ac.uk 
Running head: EFFECTIVE TALENT DEVELOPMENT: A COACH'S VIEW

\section{Abstract}

24 Talent development (TD) is widely recognised as a non-linear and dynamic process, with psychology a key determinant of long-term success in sport. However, given the role that positive characteristics play in the TD process, there is a relative dearth of research examining the psychological characteristics that may derail development. A retrospective qualitative investigation was conducted with academy coaches and directors within rugby union $(n=15)$, representing nine different elite English rugby union academies, in order to identify both positive and negative issues that influenced TD. Comprehensive support was found for existing positive constructs as facilitators of effective development. A range of inappropriately applied 'positive' characteristics were identified as having a negative impact on development. Potential clinical issues were also recognised by coaches as talent derailers.

34 It is proposed that by incorporating these potentially negative factors into existing formative assessment tools, a more effective development process can be achieved. 
Running head: EFFECTIVE TALENT DEVELOPMENT: A COACH'S VIEW

\section{Introduction}

Recent literature within talent identification and development (TID) has shown a shift away from physiological profiling and identification based on one-off performance 'snapshots', towards an acceptance of development as a non-linear, dynamic and complex process (Abbott, Button, Pepping, \& Collins, 2005; Abbott \& Collins, 2004; Phillips, Davids, Renshaw, \& Portus, 2010; Simonton, 1999). Central to this change in emphasis is the acknowledgement of the role of psychology as a key determinant in the realisation of potential and long-term success in sport. Constructs such as psychological characteristics of developing excellence (PCDEs; MacNamara, Button, \& Collins, 2010a, 2010b), growth mindset (Dweck, 2006), grit (Duckworth, Petersen, Matthews, \& Kelly, 2007) and selfregulation (Toering, Elferink-Gemser, Jordet, \& Visscher, 2009) have all been deemed pivotal in enabling athletes to negotiate the pathway to excellence in a range of performance domains, essentially providing the skills individuals need in order to negotiate key developmental opportunities and challenges (MacNamara et al., 2010a, 2010b; van Yperen, 2009).

However, given the facilitative role that these constructs and positive characteristics play in talent development (TD), it is perhaps curious as to the relative dearth of research examining the psychological characteristics and constructs that may hinder or derail the TD process. Such an approach has been used to good effect within the field of business leadership and organisational psychology, whereby Hogan and colleagues identified a range of 'dark side' characteristics and attributes that were likely to contribute to the derailment of managerial talent (Hogan \& Hogan, 2001; Hogan \& Holland, 2003; Nelson \& Hogan, 2009). Rather than being purely an absence of positive qualities, these "dysfunctional dispositions" (p.10, Nelson \& Hogan, 2009) have been associated with poor social and occupational performance (Hogan \& Hogan, 2001), degrading whatever skills and competencies may be 
Running head: EFFECTIVE TALENT DEVELOPMENT: A COACH'S VIEW

initially present (Nelson \& Hogan, 2009); as such, their impact needs to be mitigated.

Adopting such an approach to TD may be of great merit, as failure to achieve elite sporting success may be as much a function of these 'dysfunctional dispositions' as it might the absence of those positive psychological characteristics already shown to be determinants of athletic success.

It may also be that an overabundance or inappropriate emphasis on positive characteristics of development (for example, the psychological skills and characteristics identified as positive features of the development process (e.g., Abbott et al., 2005; Collins \& MacNamara, 2012; Gould, Dieffenbach \& Moffett, 2002)), may, in certain circumstances, act to limit rather than enhance progress (MacNamara \& Collins, 2014). As such, the scope for the inappropriate and maladaptive application of seemingly adaptive constructs becomes apparent and is worth considering. For example, taking the PCDE of commitment to excess, "over-commitment" can be displayed as a series of attitudes, behaviours and emotions that characterise a person working harder than formally required, often driven by a need for approval and recognition (Hetland, Saksvik, Albertsen, Berntsen, \& Henriksen, 2012). Such an effort-reward imbalance (Siegrist, 2001) can be deemed a precursor to maladaptive perfectionism (Flett \& Hewitt, 2002, 2005); an issue associated with athlete burnout (Hetland et al., 2012; Zhang, Gan \& Cham, 2007).

The role of perfectionism in sport is complex, as many sports, especially at elite level, require near-flawless performances to be deemed successful (Flett \& Hewitt, 2005). Yet despite some dimensions of perfectionism contributing to positive outcomes (Hill, Hall, Appleton \& Kozub, 2008; Slaney, Rice \& Ashby, 2002), it is primarily recognised as a negative factor that contributes to maladaptive behavioural outcomes (Flett \& Hewitt, 2002), leading to burnout (Gustafsson, Hassmén, \& Hassmén, 2011; Raedeke, 1997) and ultimately the derailment of talent. 
Running head: EFFECTIVE TALENT DEVELOPMENT: A COACH'S VIEW

As an integral component of grit, passion has also been demonstrated to have both adaptive and maladaptive consequences. Vallerand et al. (2003) proposed a dualistic model of passion; harmonious passion being a motivational force resulting in autonomous and willing engagement of activities, whilst obsessive passion - despite being a strong motivational force - controls the individual and drives them towards the activity (Gustafsson et al., 2011). Athletes harmoniously-passionately involved in their sport are more likely to experience positive affect than those who are involved obsessively-passionately (Vallerand et al., 2003, 2006). Negative affect has been shown to be a predictor and symptom of burnout in elite athletes (Lemyre, Treasure, \& Roberts, 2006), whilst athletes scoring high on obsessive passion may be more susceptible to burnout than their more harmoniously obsessive counterparts (Gustafsson et al., 2011).

As well as these 'dual effect' issues, MacNamara and Collins (2014) also identified a range of characteristics that negatively impact on an individual's progression in sport and on their psychosocial adjustment. These may manifest as behavioural disorders that can undermine sporting performance (Singer \& Janelle, 1999) and impact upon the ability to respond to developmental challenges. For example, individuals with high levels of fear of failure have been shown to adopt avoidance strategies such as self-handicapping (Rhodewalt \& Vohs, 2007; Elliot \& Church, 2003) whereby obstacles to performance are created or claimed in a bid to downplay any perceived lack of ability. Similarly, extreme shyness (cf. Baker \& Horton, 2004) and social anxiety often result in avoidance strategies and inability to seek social support (Zeidner \& Matthews, 2007).

As another potential area for talent derailment, clinical mental health issues such as depression and anxiety have also been demonstrated to have a potentially negative effect upon development through the employment of avoidance strategies (Grant et al., 2013). Athletes are increasingly seen as being no less susceptible to mental illness than general 
Running head: EFFECTIVE TALENT DEVELOPMENT: A COACH'S VIEW

113

114

115

116

117

118

119

120

121

122

123

124

125

126

127

populations (Markser, 2011), and this is reflected in the current high profile of mental illness within elite sport. This is particularly pertinent for TD, as half of all lifetime cases of mental illnesses a recognised to begin by the age of 14, and three quarters by the age of 24 (Kessler et al., 2005; MacNamara \& Collins, in press); thus coinciding with the age range of most talent development programmes. As such, the investigation of clinical mental health issues as a potential derailer should prove a fruitful line of enquiry.

In an attempt to provide a formative assessment tool, MacNamara and Collins (2011) developed the PCDE Questionnaire (PCDEQ); a psychometric tool that provides a basis from which to formatively assess and apply positive intervention strategies within a TD setting. However, in its current form the PCDEQ fails to address 'dark side' characteristics. In order to improve the efficacy of this process, a comprehensive assessment of characteristics associated with effective talent development is required that discerns and caters for both the positive and negative factors. As such, the purpose of this study was twofold; firstly to provide support for the role of PCDEs as facilitative of effective development and secondly to identify maladaptive psychological characteristics and behaviours that may limit the capability of developing to achieve long term elite-level success, with the long term objective of incorporating all these factors into a more 'complete' version of the PCDEQ.

\section{Method}

\section{Participants}

This study set out to investigate the range of psychological characteristics and associated behaviours that impact upon the TD process through a series of cross-sectional, retrospective qualitative interviews. Despite the acknowledged limitations relating to truthfulness and self-report bias (Amis, 2005; Patton, 2002), this method has been widely adopted in sport psychology literature (e.g., Gould et al., 2002), as a way of identifying phenomena and ordering the social world (Atkinson \& Delamont, 2005). A purposive, 
Running head: EFFECTIVE TALENT DEVELOPMENT: A COACH'S VIEW

criterion-based sampling approach was adopted, whereby potential participants were identified based upon their coaching qualifications, experience, and role, in a bid to glean a high level of information-rich data. The sport of rugby union was selected for several key reasons: as a team sport, the number of athletes that pass through the system potentially offer a greater resource from which to draw from; the academy structure within the sport facilitates extensive contact between coach and athlete on a regular, often daily basis; and as a highprofile achievement domain, rugby union academies have produced a succession of world class elite level players. Based on this reasoning, the academies of all 12 clubs within the Aviva Premiership (England's top-flight competition) were invited to take part in the study, with three clubs unable to due to prior commitments.

Semi-structured interviews were conducted with academy directors and head coaches $(n=15)$, all of whom played an active day-to-day role in the coaching and management of aspiring elite rugby union players. Academy directors and coaches were sampled in a bid to draw upon their unique insights and understanding of the TD process in rugby union. The ages of the coaches ranged from 26 to 63 years $(M=38.9$ years, $S D=11.1$ years), all with between 3 and 32 years elite level coaching experience $(M=13.1$ years, $S D=9.2$ years). As a male professional sport, all participants in this study, along with the athletes they discussed, were also male.

\section{Procedure}

Ethical approval was obtained from the authors' institutional ethics committee prior to the commencement of the study, with informed consent obtained from all participants and confidentiality assured. A semi-structured interview guide was developed, designed to explore the different psychological aspects that may facilitate or derail talent development processes, along with follow-up probes and prompts to elicit data in specific areas of interest. Reflecting the findings within the literature, the interviews comprised of three distinct 
Running head: EFFECTIVE TALENT DEVELOPMENT: A COACH'S VIEW

sections: positive (e.g., "How do these behaviours and characteristics differ from other athletes who have not gone on to be successful at elite level?"), dual-effect (e.g., "Can you describe examples of when athletes have taken positive characteristics to excess, or perhaps applied them inappropriately?") and negative characteristics and behaviours (e.g., "What do you think are the psychological or behavioural factors that stop an athlete making the most of their ability?"). These a priori constructs were adopted in order to help guide the analysis process by providing a provisional understanding from which themes can emerge; thus adopting an abductive approach as opposed to purely inductive or deductive one (cf. Ali \& Birley, 1999; Atkinson \& Delamont, 2005; Patton, 2002). Deductive analysis was also carried out to test support for the utilisation of PCDEs, using the framework generated by MacNamara and colleagues in their initial study (cf. MacNamara et al., 2010a). Interviews lasted between 67 and 93 minutes ( $M=79.5$ minutes, $S D=8.2$ minutes), preceded by an introduction and briefing, and were conducted at the participants' respective talent development environments. The interviews were conducted by the primary researcher, who had previous experience in interviewing, qualitative methods, and talent development.

\section{Data Analysis}

Interviews were transcribed verbatim and returned for participant checking along with the researcher's interpretations to establish credibility (Amis, 2005), with one transcript being returned with minor alterations to aid clarity of the original meaning. Following the recommendations of Côté, Salmela, Baria, \& Russell (1993), a standard content analysis was undertaken, with meaning units created from raw data segments; these meaning units were then grouped into emergent categories. This process was repeated in order to generate higher-order themes until theoretical saturation was reached, whereby all new meaning units analysed fit into the existing coding structure (Patton, 2002; Strauss \& Corbin, 1998). In recognition of the researcher's role as the primary data collection tool and therefore the scope 
Running head: EFFECTIVE TALENT DEVELOPMENT: A COACH'S VIEW

for potential bias (Amis, 2005), an independent researcher experienced in both qualitative analysis and talent development was invited to critically analyse the emergent categories to ensure they reflected the participants' quotations, thus aiding credibility, confirmability, and dependability. Where this resulted in disagreement between the researchers, interpretations were put forward until an agreed explanation was found. This process resulted in the amendment of three category labels that were felt to better represent their subsequent meaning units (e.g., "limiting effects of perfectionism" became "managing perfectionistic tendencies"), thus suggesting a high degree on congruence. A deductive analysis was also undertaken on the data segments, with the specific purpose of establishing further support for the application PCDEs in TD, utilising the framework established by MacNamara and colleagues (MacNamara et al., 2010a).

\section{Results}

The purpose of this study was to identify the range of psychological characteristics that impacted positively on TID, those that had potentially both a positive and negative effect, and those that were deemed to be detrimental to development. As such, and reflecting the structure of the interview guide, this section is presented in three stages: positive psychological characteristics, dual-effect characteristics and negative psychological characteristics. An overview of the emergent themes is presented in Table 1, with the themes italicised within the text to aid clarity.

\section{Positive Psychological Characteristics}

Support for the application of a range of PCDEs by developing athletes who have since gone on to achieve success was pervasive throughout the data and across all participants. For example, commitment was described as being demonstrated in a wide variety of ways, including discipline (e.g., “...they [successful athletes] have been massively disciplined." (Coach 14)), doing the extras (e.g., "I would say it does come down to those 
Running head: EFFECTIVE TALENT DEVELOPMENT: A COACH'S VIEW

213

214

215

216

217

218

219

220

221

222

223

224

225

226

227

230

231

232

233

234

235

236

237

who are prepared to do the extra are generally the ones who do succeed, and that's across the board." (Coach 10)), motivation and drive (e.g., "I think the ones that really stand out are the ones who you can see completely pushing themselves to their limits even when there's no coaches or teammates around watching." (Coach 8)), a positive work ethic, and the athlete's ability to sacrifice. It was also recognised more generally in terms of overall commitment. For example, coach 9 described how:

They've got to commit to developing themselves, because - we mentioned it earlier you can be a passenger and you can do okay or you can take control and ask how can I do more, how can I be better, where can I find improvement? (Coach 9)

Planning and self-organisation (e.g., arriving early and prepared for training sessions) were also deemed important in order to manage workloads and maximise developmental opportunity, whilst quality practice and focus and distraction control were identified by coaches as key characteristics that positively influenced developmental efficacy, as highlighted by coach 11:

[Name of player]'s short term goals, he was very focussed on them. He knew exactly what he wanted to achieve in a particular session. If that meant he stayed out there for two hours, then he'd stay there for two hours, because he would keep going until he got it right. (Coach 11)

Resilience was also highlighted as both a key requirement and a differentiator between those who go on to achieve success and those that don't. It was seen as enabling individuals to cope with the challenging demands of the talent development environment and facilitating perseverance despite initial failures:

And that resilience is a massive thing and it shows itself within a training session when they just want to go again, and again, or in selection and they're not picked, but they'll still be there, they'll still be keen and enthusiastic. (Coach 9) 
Running head: EFFECTIVE TALENT DEVELOPMENT: A COACH'S VIEW

Realistic performance evaluation and high levels of self-awareness were perceived to be fundamental to effective development, as an accurate self-assessment of the athlete's own ability was seen as forming the basis of effective goal setting strategies. As part of formal review processes, coaches described the successful athletes as having a very small differential between their own perception of their ability and the coaches' view (e.g., "Their differential tends to be quite small and they tend be often be harder on themselves and probably put themselves down a little bit when they're marking themselves and scoring themselves in different areas." (Coach 8)). The coaches also noted that those successful athletes were often harsh in their assessments, but that this did not impact on their confidence and self-belief (e.g., "I think it doesn't seem to necessarily affect their overriding belief that they've still got something that other people haven't." (Coach 5)).

In line with the existing literature, self-regulation was viewed as a key strategy employed by successful athletes. Successful athletes reportedly demonstrated independence and ownership of their own development, taking responsibility for important decisions: We sat in interviews with these players and parents, and parents are driving a lot of the education side of it and the comfort side of it, because that's what they feel comfortable with, and the really good lads at some point will take ownership of it and say, actually, this is what I want to do, I understand the pitfalls, but this is what I want to do. (Coach 1)

These athletes were also proactive in terms of seeking out and engaging in further developmental opportunities and were regularly seen asking questions in order to further their own knowledge, as highlighted by the example "You see a cycle of people who just keep asking questions, and those hard working ones, they'll always ask questions once they understand something, and then push you for how can I have improvement" (Coach 9). Such self-regulation was also evident in the way many of the PCDEs were deployed. Coach 6 
Running head: EFFECTIVE TALENT DEVELOPMENT: A COACH'S VIEW

263

264

265

266

267

highlights the difference in an applied setting between possessing certain characteristics and deploying them effectively:

[Name of player] was a good example, I guess... when it came to reviewing his performances you had sit him down and make him do it. It's not that he couldn't, he was actually quite good at analysing his own game, he just didn't like to do it unless he had to, whereas some of the other kids, especially the better ones, they were probably more eager to do it. (Coach 6)

Qualities associated with a growth mindset were widely recognised by the coaches in those athletes who then went on to achieve success, with learning from mistakes, engaging with challenge and reacting positively to setbacks such as de-selection all consistently demonstrated, as exemplified in the following scenario: [Name of player] he's on loan at a National 2 club, which he's not happy about. He thinks he should be playing Premiership, but his coping strategy is to look at what he can do better and put more effort in to it. When he's on the pitch and National 2, it's to put more work in than anyone else and be the best player on the field. (Coach 15)

As a fundamental component of grit, passion, energy and enthusiasm was widely acknowledged by the coaches as a quality of those athletes who go on to achieve success, with its potential to positively influence the opinion of coaches.

So as I say, [Name of player] arrives at every first team session with energy and enthusiasm, the work rate, the right attitude, positivity and the coaches see that, so they immediately go he's a good kid, he's working hard - all those things. (Coach 15)

The remaining component - perseverance - was demonstrated throughout as both commitment and resilience behaviours, and was therefore classified as such within the analysis process. Other positive psychological characteristics reportedly exhibited by those athletes who then went on to achieve success included a high level of developmental 
Running head: EFFECTIVE TALENT DEVELOPMENT: A COACH'S VIEW

awareness (i.e., knowing what is required in order to develop as a player), consistency in their positive behaviours and associating with the environment's cultural identity.

\section{Dual-Effect Psychological Characteristics}

Obsessive passion was identified has having a negative impact upon development and/or performance, whereby athletes displayed excessive behaviours seemingly driven by a need to improve, such as over-analysing techniques.

[Name of player] would start thinking about techniques and stuff. If he missed a kick, he'd be thinking "well I fell off that to the right, my head was too far up" or whatever.... he needs to concentrate on the whole process but he goes in to the details. He'll focus so hard on getting that one bit right that he missed that he can forget another bit. (Coach 11)

Similarly, over-commitment was described, with a recognition amongst coaches that, if left unmanaged, it could be potentially detrimental to an athlete's development, with the athlete partaking in well-meaning but misguided developmental activities, as demonstrated by coaches 6 and 8:

If we set him some physical targets to hit, he'll hit them, however he's going to get them and hit them, whereas for us, all we're doing is risking that he gets injured, because if he's not doing it in the right way, he's that determined, he'll still get there because that's his characteristics. (Coach 6) I think [Name of player] is a good example again, the S\&C guy had to keep a really close rein on him because he just thought that more was better, and he would just do more and more on his days off.... he just felt that the more he did, the better he'd get. That's one of the downside to that type of intrinsic drive, you know? (Coach 8) Echoing the sentiments of the previous dual-effect characteristics, the role of perfectionism was seen as having potentially detrimental aspects to both development and 
Running head: EFFECTIVE TALENT DEVELOPMENT: A COACH'S VIEW

313

314

315

316

317

performance. Managing perfectionism in the environment was seen as fundamental to maintaining its adaptive effects and minimising any maladaptive consequences, rather than attempting to address the processes that drive perfectionistic tendencies. The potential impact of perfectionism on development is illustrated by coach 15 :

A guy [Name of player] who's played for England on the wing, now at [Name of club], he's the first guy on the training field, he's the last guy off the training field, he'll pass for two hours of his right, two hours off his left, rear foot passing - he'll just rep it out and rep it out and rep it out. And actually the big thing he needs to work on is weight gain, but you can't get him off his feet so it becomes very difficult to do that.... So I think it is about getting to know the individual, and with [Name of player] we got it wrong early on because we didn't know his personality well enough. We said okay, left foot kicking, off you go. Then he's out there until it's dark, so we were like right, okay, we've got to change this. So being aware of that is critical. (Coach 15)

\section{Negative Psychological Characteristics}

One of the primary issues raised as a negative characteristic was the employment of avoidance-based coping strategies by those athletes who didn't go on to achieve elite level success in rugby union. Many of these athletes were reported to use avoidance strategies to avoid possible failure, with coach 8 highlighting the detrimental impact this can have on their development and progression:

Their drive to avoid messing up is greater than their drive to say "I want to put myself forward"... they end up getting released from environments because they're trying not to fail because if they do something wrong it shows up, but then they're not putting themselves forward to do things. (Coach 8)

In response to failures and unsuccessfully negotiating challenge, the less successful athletes reportedly often sought to employ external attribution as a strategy to disassociate themselves 
Running head: EFFECTIVE TALENT DEVELOPMENT: A COACH'S VIEW

with the recent or potential failure, both on and off the field, as demonstrated in Coach 13's example, "It's how they address that situation - "I'm injured, so my body fat's gone".

There's the little excuses there and it's how they address it", or that of Coach 9:

"How do you think it went?" "Well he left me [isolated on the pitch] so it was difficult for me to..." There's not really an acceptance of yeah, it happens, how do I improve it, let's move on. It's "He should have come up and pressed with me, but I thought I was okay". (Coach 9)

Similarly, impression management and affirmation seeking were also employed by those less successful athletes to detract from perceived failures and weaknesses, for example: "Some of the lads think 'yeah, I'll score myself harshly, 'cos that's what the coach wants to see"” (Coach 13).

A lack of commitment to their own development was observed by the coaches across those who failed to progress, manifesting itself in a variety of ways such as amotivation and doing the minimum:

If I've just got to do this rugby session this week, if I'm just doing the session - I won't try and add to the session, I won't set myself the challenge to perform in front of these coaches or train with the first team players - I'm just going to get through it. But I'll develop because I'm getting through it. And there's that thought process and those players don't quite make the transition. (Coach 9)

Similarly, inconsistency was cited as being detrimental to an athlete's development, with coach 3 describing its impact on one athlete's fitness:

So you get to [Name of player] who came in and he was really fat and overweight but worked really hard to start with, and then it was too hard to keep going so he gradually went back to his start point, really. (Coach 3) 
Running head: EFFECTIVE TALENT DEVELOPMENT: A COACH'S VIEW

In line with behaviours representing a lack of commitment, behavioural incongruence was recognised by coaches as prevalent in those athletes who didn't go on to achieve success, essentially 'talking the talk' but not 'walking the walk', with some athletes demonstrating an inability to sacrifice:

All of them come with the goal of I want to play for England or I want to play for the Lions and there's not many of them that back that up with the behaviours that are required.... I've seen guys who are willing to compete in an environment where there's other people there, but they're not so willing to compete when it's just them. (Coach 8) Throughout the interviews, coaches highlighted the apparent lack of awareness amongst the less successful athletes. A lack of self-awareness and poor performance evaluation were cited as having a detrimental impact on development, such as in the following example cited by coach 15 :

We've got a lad in our programme who's a talented kid but his perception of himself he works hard and he does all the things well - but his perception of himself is not in line with actually where he is. His belief is that he should be playing for the first team, he should be doing this, and managing him in a loan club environment is very difficult. Managing him through his development becomes very difficult because he sees the standard of rugby he's playing as beneath him. Whereas what he's doing is not playing to that standard of rugby, so he's essentially beneath that. (Coach 15)

Athletes also demonstrated a lack of developmental awareness of both their own developmental pathway and in relation to other, more senior players, as demonstrated by coaches 2 and 8 :

In terms of strength and conditioning, we didn't need him to be where he wanted to be at 15 years of age. There was always a long term plan to get him to where he needed to 
Running head: EFFECTIVE TALENT DEVELOPMENT: A COACH'S VIEW

get to, and he struggled with that massively, because he wanted to be fresh all the time so that he could demonstrate his rugby ability. (Coach 2)

The one's that aren't quite at the same level, they're often not prepared to sacrifice because they can't work out in their head the link between doing something now and that delayed gratification again - they don't work out the link that doing something now will pay them back in their physical term. (Coach 8)

It was reported that these athletes who didn't go on to achieve were often unsuccessful at managing developmental transitions (unlike their more successful counterparts), often failing to overcome challenge both within their sport and away from it.

Coaches cited expectation and entitlement and an absence of developmental challenge as mechanisms for this failure, whereby early success had been achieved with little effort (e.g., physical precocity) or stakeholders (e.g., parents, schools, etc.) having "given them everything" (Coach 4). This was further supported by coach 2 :

He's had smoke blown up his arse for a hell of a lot of time because he is a talented player, but every time you try and go "what about this?" you get the strop, the derailment in every session. (Coach 2)

I could probably name five kids a year who come through who've been dominant in their age groups and they get to a place where they have some ability but when it starts getting tough and they can't run around it. (Coach 5)

A variety of mental health issues were identified has having a negative impact upon development, such as depression:

...A bit like the [Name of player] issue in terms of looking for a way out. Home life issues which are causing issues here. We get quite complex home life situations which can create a lot of stress for the players while they're here. It ends up with depression and stuff like that. [Name of player] would be one of those, you'd say at various points 
Running head: EFFECTIVE TALENT DEVELOPMENT: A COACH'S VIEW

he goes in to a big sort of depression, and it's very hard to learn how to deal with him. (Coach 1)

Eating disorders and in one extreme case, suicidal tendencies were also identified by the coaches. Whilst acknowledging their existence and potential negative impact on development, the coaches accepted that their knowledge of the subject was very limited, often referring athletes to appropriate specialists, as described by coach 8 : We're working with a psychologist with it at the moment because [Name of player]'s very emotionally unstable around games, particularly after games, being tearful and crying after games, which has concerned me and I don't know what the root of that is. I'm trying to work out at the moment the best way around helping him and finding out what it is, working with our psychology guys trying to help him to do that better. (Coach 8)

The prevalence and awareness of mental health issues was also discussed. Despite coaches acknowledging the impact of mental health on developmental athletes, several of them raised the question of its true extent within the sport due to a poor understanding and awareness, for example: "I think you could probably, with a little bit more education towards the guys in charge of the programme, identify those things far earlier." (Coach 15). Despite this, several coaches noted an increased prevalence in mental health issues: "Whether it's here or whether there's an underlying issue prior to coming in to here, there's definitely and increased prevalence of those sort of mental health issues." (Coach 4)

\section{Discussion}

There was wide-ranging support across the data for the application of PCDEs by successful developing athletes within rugby union TDEs, reflecting findings in existing literature. These were identified by the coaches as being operationalised in a variety of ways by different individuals at different times, again supporting previous findings (MacNamara et 
Running head: EFFECTIVE TALENT DEVELOPMENT: A COACH'S VIEW

al., 2010a, 2010b). For example, several coaches discussed high levels of commitment, focus and attention to detail in developing athletes who successfully graduated from their respective academies. However, coach 15 described an example of one player who did not display these characteristics initially and as a result was released from the programme, but went on to display them later on in his development:

[Name of player] at [name of club] is a guy that was in the academy, was exited because he was poor on his nutritional detail, poor on various things so they said we're not wasting any more time with you. Then they had to resign him for [fee] from [name of club] when he finally got himself in gear. (Coach 15)

This demonstration of non-linear athlete development and resultant premature de-/nonselection has been recognised in previous literature (cf. Abbott \& Collins, 2004; Abbott et al., 2005), and raises the issue of support networks such as feeder clubs to facilitate and capitalise on this late development. However, this valid and necessary discussion is beyond the scope of this paper. Of the PCDEs identified previously (MacNamara et al., 2010a), only imagery was not reported in this study, suggesting that it was either not operationalised by the developing athletes at this stage, or alternatively that it was not recognised by the coaches. This is perhaps unsurprising, given the potential lack of overt and observable behaviours associated with this primarily cognitive process. It is an issue which merits attention, however; especially given the potential power of imagery related interventions and actions in enhancing performance (Orlick \& Partington, 1988; Taylor \& Shaw, 2002).

Self-regulated learning strategies are predictive of both superior athletic performance and enhanced motivation (Zimmerman \& Kitsantas, 1996; 2007), and were widely recognised throughout the data in those athletes who then went on to achieve success. This reflects Toering and colleagues' suggestion that self-regulation is important for youth athletes in order to maximise both developmental opportunity and their own potential (Toering et al., 
Running head: EFFECTIVE TALENT DEVELOPMENT: A COACH'S VIEW

2009; Toering et al., 2011). Self-promoted PCDEs such as goal setting, self-organisation, planning and performance evaluation are in themselves recognised self-regulated learning strategies (Zimmerman, 2006; Zimmerman \& Kitstantas, 2007), thus highlighting the role of self-regulation as the strategy of choice for the effective deployment of PCDEs. Reflecting this, an absence of independence and ownership - qualities associated with effective selfregulation - were reported in those athletes who were unsuccessful in achieving their longterm goals, as was an absence of PCDEs, such as lack of commitment or an inability to cope with pressure.

Qualities associated with the 'growth mindset' construct (Dweck, 2006) were a key feature of reports describing those athletes who went on to achieve success. Similarly, 'grit' (Duckworth et al., 2007) was also prevalent. However, when examining the descriptions of these effective behaviours, it becomes apparent that characteristics such as engaging with challenge, learning from mistakes and reacting positively to setbacks are operationalised through the deployment of PCDEs and self-regulatory processes. For example, self-regulated learners have been shown to display persistence during learning (Zimmerman, 1990), realistic performance evaluation is fundamental to learning from mistakes as part of a reflective process and the self-motivational beliefs associated with passion and engaging with challenge are linked to self-regulatory processes (Zimmerman, 2006).

A range of dual effect characteristics were recognised in both successful and unsuccessful developing athletes. Coaches recognised the need for passion as a motivational force within athletes to help drive their development, acting as a metaphorical 'glue' that helps 'stick' the athlete to the developing process, thus enabling them to persevere with key developmental activities that may not be themselves inherently enjoyable (Ericsson et al., 1993). However, coaches also reported situations where this passion had been taken to excess, i.e., obsessive passion (cf. Vallerand et al., 2003). This manifested itself as instances 
Running head: EFFECTIVE TALENT DEVELOPMENT: A COACH'S VIEW

where athletes focussed too much on a single aspect of their performance or development and lost focus of their overarching aims - the 'bigger picture'. Interestingly, despite its reported associations with injury burnout in the literature (Akehurst \& Oliver, 2013; Quested \& Duda, 2011), this was something that the coaches felt wasn't the case in their environments, with a range of safeguards, support and interventions applied when deemed necessary. This mediation of dual effect characteristics was also evident in cited cases of perfectionism, whereby perfectionistic tendencies in individuals were managed in a bid to minimise any potential maladaptive effects. Within perfectionism literature, there is a common consensus that when the overlap between perfectionistic concerns and perfectionistic strivings is controlled for, perfectionistic strivings show positive correlations with adaptive characteristics, with the positive associations of perfectionistic striving often supressed by the negative association of perfectionistic concerns (Gotwals, Stoeber, Dunn, \& Stoll, 2012; Hill, Huelsman, \& Araujo 2010; Stoeber, 2011). If, however, as suggested, the way to increase the adaptive function of perfectionism is to reduce the level of perfectionistic concern rather than increase the level of perfectionistic strivings (Stoeber \& Janssen, 2011), yet both dimensions of perfectionism are significantly correlated (Dunkley, Zuroff, \& Blankstein, 2003; Stoeber \& Janssen, 2011), it follows that the net effect of perfectionism would remain relatively unchanged. So from an applied perspective, there is perhaps merit to the coaches' approach to mediating the outcome of perfectionistic tendencies, rather than attempt to address the processes behind them.

A range of characteristics that negatively impacted upon talent development were reported in those athletes who didn't go on to achieve success, with several of these reflecting an absence of positive characteristics, such as a lack of commitment or lack of developmental awareness. These less successful athletes employed avoidance-based strategies rather than the self-regulated application of PCDEs as discussed earlier. Crucially, the efficacy of the TD 
Running head: EFFECTIVE TALENT DEVELOPMENT: A COACH'S VIEW

511

512

513

514

515

516

517

518

519

520

521

522

523

524

525

526

527

528

529

530

531

532

533

534

535

process could be said to be dependent upon the effectiveness of the interaction between the athlete and the environment, and the consequence of employing many of these strategies was that it led to either a failure to engage with developmental challenge and opportunity (e.g., avoidance), or in a reduced effectiveness of this interaction (e.g., self-handicapping).

Similarly, mental health issues were also identified as impacting upon developmental processes, often resulting in time away from the environment for the athlete involved and a reduced effectiveness of interaction with it when present. Coaches recognised the increased prevalence of mental health issues in rugby union, but suggested a lack of awareness at both a macro and micro level. Examples were cited whereby individuals were referred to psychologists and doctors by the coach in order to receive support for potential mental health issues. However, if, as was reported, these coaches (and potentially the system as a whole) have a poor awareness of the issues and symptoms associated with mental health in young people, then diagnosis and referral of developing athletes to the appropriate support will be potentially sub-optimal. Further research on the awareness and impact of mental health issues on developing athletes is therefore necessary.

The role of motivation appears to underpin many of the characteristics and choices of adopted strategies in successful athletes as well as their less successful counterparts, such as its impact upon commitment levels (Ryan \& Deci, 2000; Weiss, Weiss, \& Amorose, 2010) and the associated behaviours. Coping strategies such as avoidance, external attribution and impression management are often associated with a fear of or a need to avoid failure (Elliot \& Church, 2003; Rhodewalt \& Vohs, 2007; Schultheiss \& Brunstein, 2007), and within a talent development context, parents of aspiring elite athletes have been shown to contribute to the development of fear of failure through their high expectations, controlling behaviours and punitive measures (Sagar \& Lavallee, 2010). It is therefore possible that other stakeholders such as coaches, teachers and peers may also contribute to its development through similar 
Running head: EFFECTIVE TALENT DEVELOPMENT: A COACH'S VIEW

mechanisms. As such, the role of these external stakeholders and their long-term effect upon an athlete's motivational disposition warrants closer scrutiny.

Given the scope and diversity of different psychological characteristics and

behaviours that have been demonstrated to impact both positively and negatively on the talent development process, even if the development of positive characteristics is embedded into the TDE, it is unlikely to remedy the whole scenario. Due attention must be given to how to effectively manage the dual effect and negative characteristics and behaviours, as these will, inevitably, manifest for at least some athletes at some stage during their development. As such, the need for a formative assessment tool from which to base effective interventions is obvious. The existing PCDE Questionnaire (MacNamara \& Collins, 2011) goes some way to address this, but as this study shows, only assessing PCDEs ignores a broad range of characteristics and behaviours that this study demonstrates also influence talent development efficacy. As such, we propose the expansion of the PCDE Questionnaire to incorporate these issues - namely the dual-effect and negative characteristics - thus offering more comprehensive monitoring and formative assessment, greater scope for effective intervention and thus ultimately a more efficacious development process.

\section{Conclusion}

This study sought to identify the range of psychological characteristics, attitudes and behaviours that impact on the talent development process within rugby union academies both positively and negatively. In line with existing literature, a range of positive characteristics, negative characteristics and dual-effect characteristics were identified through a series of retrospective interviews with rugby union coaches and academy directors. Based on these findings, we propose the expansion of the PCDE Questionnaire to incorporate these negative and dual-effect characteristics, thus providing a more comprehensive formative assessment tool from which to base effective interventions. 
Running head: EFFECTIVE TALENT DEVELOPMENT: A COACH'S VIEW

561

There are some limitations associated with this study owing to its retrospective

562 design, namely reliability, truthfulness and self-report bias (Amis, 2005; Patton, 2002), and as

563 such, future longitudinal research is recommended to support these findings. Alongside this,

564 we recommend further research in to the awareness and impact of mental health issues in

565 talent development processes, as well as similar exploratory research in to other talent

566 development domains (e.g., the performing arts, individual sports, other team sports etc.),

567 along with incorporating different perspectives (such as the athletes themselves and their

568 parents) in a bid to identify a comprehensive range of influencing factors. 
Running head: EFFECTIVE TALENT DEVELOPMENT: A COACH'S VIEW

\section{References}

570 Abbott, A., Button, C., Pepping, G., \& Collins, D. (2005). Unnatural Selection: Talent 571 Identification and Development in Sport. Nonlinear Dynamics, Psychology, and Life $572 \quad$ Sciences, 9(1), 61-88.

573 Abbott, A., \& Collins, D. (2004) Eliminating the dichotomy between theory and practice in 574 talent identification and development: considering the role of psychology. Journal of $575 \quad$ Sports Sciences, 22, 395-408.

576 Akehurst, S., \& Oliver, E.J. (2013). Obsessive passion: a dependency associated with injury577 related risky behaviour in dancers. Journal of Sport Sciences, 1-9. doi:10.1080/02640414.2013.823223

579

580

581

582

583

584

585

586

587

588

589

590

Ali, H., \& Birley, S. (1999). Integrating deductive and inductive approaches in a study of new ventures and customer perceived risk. Qualitative Market Research: An International Journal, 2(2), 103-110.

Amis, J. (2005). Interviewing for case study research. In: D.L. Andrews, D.S. Mason, \& M.L. Silk (Eds.), Qualitative Methods in Sports Studies (pp. 104-138). Oxford, UK: Berg.

Atkinson, P., \& Delamont, S. (2005). Analytical Perspectives. In: N.K. Denzin \& Y.S. Lincoln (Eds.), The Sage Handbook of Qualitative Research (3rd ed.) (pp. 821-840). London: Sage.

Baker, J., \& Horton, S. (2004). A review of primary and secondary influences on expertise. High Ability Studies, 15(2), 211-228.

Collins, D., \& MacNamara, Á. (2012). The rocky road to the top: Why talent needs trauma. Sports Medicine, 42(11), 907-914. doi:10.2165/11635140 
Running head: EFFECTIVE TALENT DEVELOPMENT: A COACH'S VIEW

591 Côté, J. (1999). The Influence of the Family in the Development of Talent in Sport. The $592 \quad$ Sports Psychologist, 13, 395-417.

593 Côté, J., Salmela, J.H., Baria, A., \& Russell, S.J. (1993). Organising and interpreting $594 \quad$ unstructured qualitative data. The Sport Psychologist, 6, 55-64.

595

596

597

598

599

600

601

602

603

604

605

606

607

608

609

610

611

612

Duckworth, A.L., Peterson, C., Matthews, M.D., \& Kelly, D.R. (2007). Grit: Perseverance and passion for long-term goals. Journal of Personality and Social Psychology, 93, 10871101.

Duckworth, A.L., \& Quinn, P.D. (2009). Development and validation of the Short Grit Scale (GRIT-S). Journal of Personality Assessment, 91(2), 166-174.

Dunkley, D.M., Zuroff, D.C., \& Blankstein, K.R. (2003). Self-critical perfectionism and daily affect: Dispositional and situational influences on stress and coping. Journal of Personality and Social Psychology, 84, 234-252. doi:10.1037/0022-3514.84.1.234

Durand-Bush, N., \& Salmela, J.H. (2002). The Development and Maintenance of Expert Athletic Performance: Perceptions of World and Olympic Champions. Journal of Applied Sport Psychology, 14, 154-171.

Dweck, C.S. (2006). Mindset: The new psychology of success. New York: Random House

Ericsson, K.A., Krampe, R., \& Tesch-Romer, C. (1993). The role of deliberate practice in the acquisition of expert performance. Psychological Review, 100(3), 363-406.

Elliot, A. J., \& Church, M. A. (2003). A motivational analysis of defensive pessimism and self-handicapping. Journal of Personality, 71, 369-396.

Flett, G. L., \& Hewitt, P. L. (2002). Perfectionism and maladjustment: An overview of theoretical, definitional, and treatment issues. In G. L. Hewitt \& P. L. Flett, (Eds.), 
Running head: EFFECTIVE TALENT DEVELOPMENT: A COACH'S VIEW

Perfectionism: Theory, research and treatment (pp. 5-29). Washington, DC: American Psychological Association.

Flett, G. L., \& Hewitt, P.L. (2005). The perils of perfectionism in sports and exercise. Current Directions in Psychological Science, 14(1), 14-18.

Gotwals, J.K., Stoeber, J., Dunn, J.G.H., \& Stoll, O. (2012). Are perfectionistic strivings in sport adaptive? A systematic review of confirmatory, contradictory and mixed evidence. Canadian Psychology, 53(4), 263-279.

Gould, D., Dieffenbach, K., \& Moffett, A. (2002). Psychological Characteristics and Their Development in Olympic Champions. Journal of Applied Sports Psychology, 14, 172-204.

Grant., D.M., Wingate, L.R., Rasmussen, K.A., Davidson, C.L., Slish, M.L., RhoadesKerswill, S., ... Judah, M.R. (2013). An examination of the reciprocal relationship between avoidance coping and symptoms of anxiety and depression. Journal of Social and Clinical Psychology, 32(8). 878-896.

Gustafsson, H., Hassmén, P., \& Hassmén, N. (2011). Are athletes burning with of passion? European Journal of Sport Sciences, 11, 387-395.

Helsen, W.F., Starkes, J.L., \& Hodges, N.J. (1998). Team Sports and the Theory of Deliberate Practice. Journal of Sport and Exercise Psychology, 20, 12-34.

Hetland, H., Saksvik, I. B., Albertsen, H., Bernsten, L. S., \& Henriksen, A. (2012). All work and no play: Over-commitment and personality among university and college students. College Student Journal, 46(3), 470-482.

Hill, A.P., Hall, H.K., Appleton, P.R., \& Kozub, S.A. (2008). Perfectionism and burnout in junior elite soccer players: The mediating influence of unconditional self-acceptance. Psychology of Sport and Exercise, 9, 630-644. 
Running head: EFFECTIVE TALENT DEVELOPMENT: A COACH'S VIEW

636

637

638

639

640

641

642

643

644

645

646

647

648

649

650

651

652

653

654

655

656

Hill, R. W., Huelsman, T. J., \& Araujo, G. (2010). Perfectionistic concerns suppress associations between perfectionistic strivings and positive life outcomes. Personality and Individual Differences, 48, 584-589. doi: 10.1016/j.paid.2009.12.011

Hogan, R., \& Hogan, J. (2001). Assessing leadership: A view from the dark side. International Journal of Selection and Assessment, 9(1), 40-51.

Hogan, J., \& Holland, B. (2003). Using theory to evaluate personality and job-performance relations: A socioanalytic perspective. Journal of Applied Psychology, 88(1), 100-112.

Kessler, R.C., Berglund, P., Demler, O., Jin, R,, Merikangas, K.R. \& Walters, E.E. (2005). Lifetime prevalence and age-of-onset distributions of DSM-IV disorders in the National Comorbidity Survey Replication. Archives of General Psychiatry, 62(6), 593-602.

Kreiner-Phillips, K., \& Orlick, T. (1993). Winning after winning: the psychology of ongoing excellence. The Sport Psychologist, 7, 31-48.

Lemyre, N. P., Treasure, D. C., \& Roberts, G. C. (2006). Influence of variability in motivation and affect on elite athlete burnout susceptibility. Journal of Sport and Exercise Psychology, 28, 32-48.

MacNamara, Á. (2011). Psychological Characteristics of Developing Excellence. In: D. Collins, A. Button \& H. Richards (Eds.), Performance Psychology: A practitioner's guide (pp. 47-64). Edinburgh: Elsevier.

MacNamara, Á., \& Collins, D. (2011). Development and initial validation of the psychological characteristics of developing excellence questionnaire. Journal of Sports Sciences, 29(12), 1273 - 1286. doi:10.1080/02640414.2011.589468 
Running head: EFFECTIVE TALENT DEVELOPMENT: A COACH'S VIEW

657 MacNamara, Á., \& Collins, D. (2014). Staying with the "Force" and countering the "Dark 658 Side": Profiling, exploiting and countering psychological characteristics in TID. The Sport $659 \quad$ Psychologist. doi:10.1123/tsp.2014-0021

660

661

662

663

664

665

666

667

668

669

670

671

672

673

674

675

676

677

678

679

MacNamara, Á., Button, A., \& Collins, D. (2010a). The Role of Psychological Characteristics in Facilitating the Pathway to Elite Performance. Part 1: Identifying Mental Skills and Behaviours. The Sports Psychologist, 24, 52-73.

MacNamara, Á., Button, A., \& Collins, D. (2010b). The Role of Psychological Characteristics in Facilitating the Pathway to Elite Performance. Part 2: Examining Environmental and Stage-Related Differences in Skills and Behaviours. The Sports Psychologist, 24, 74-96.

Markser, V.Z. (2011). Sport psychiatry and psychotherapy. Mental strains and disorders in professional sports. Challenge and answer to societal changes. European Archives of Psychiatry and Clinical Neuroscience, 261(2), 182-185. doi: 10.1007/s00406-011-0239-x

Nelson, E., \& Hogan, R. (2009). Coaching on the Dark Side. International Coaching Psychology Review, 4(1), 9-21.

Orlick, T., \& Partington, J. (1988). Mental links to excellence. The Sport Psychologist, 2, 105-130.

Patton, M.G. (2002). Qualitative research and evaluation methods ( $3^{\text {rd }}$ ed.). Thousand Oaks, CA: Sage.

Phillips, E., Davids, K., Renshaw, I., \& Portus, M. (2010). Expert Performance in Sport and the Dynamics of Talent Development. Sports Medicine, 40(4), 271-283.

Quested, E. \& Duda, J.L. (2011). Antecedents of burnout among elite dancers: A longitudinal test of basic needs theory. Psychology of Sport and Exercise, 12, 159-167. 
Running head: EFFECTIVE TALENT DEVELOPMENT: A COACH'S VIEW

680 Raedeke, T. D. (1997). Is athlete burnout more than just stress: A sport commitment model. 681 Journal of Sport and Exercise Psychology, 19, 396-417.

682

Rhodewalt, F., \& Vohs, K.D. (2007). Defensive Strategies, Motivation and the Self: A selfregulatory process view. In: A.J. Elliott \& C.S. Dweck (Eds.), Handbook of Competence and Motivation (pp. 548-565). London: Guilford Press.

Ryan, R.M., \& Deci, E.L. (2000). Self-determination theory and the facilitation of intrinsic motivation, social development, and well-being. American Psychologist, 55(1), 68-78.

Sagar, S.S., \& Lavallee, D. (2010). The developmental origins of fear of failure in adolescent athletes: Examining parental practices. Psychology of Sport and Exercise, 11, 177-187.

Schultheiss, O.C., \& Brunstein, J.C. (2007). An implicit motive perspective on competence. In: A.J. Elliott \& C.S. Dweck (Eds.), Handbook of Competence and Motivation (pp. 3151). London: Guilford Press.

Siegrist, J. (2001). A theory of occupational stress. In: J. Dunham (Ed.), Stress in the workplace: past, present and future (pp. 52-66). London: Whurr.

Simonton, D.K. (1999). Talent and Its Development: An Emergenic and Epigenetic Model. Psychological Review, 106(3), 435-457.

Singer, R. N., \& Janelle, C. M. (1999). Determining sport expertise: from genes to supremes. International Journal of Sport Psychology, 30, 117-150.

Slaney, R.B., Rice, K.G., \& Ashby, J.S. (2002). A programmatic approach to measuring perfectionism: The Almost Perfect Scales. In G.L. Flett \& P.L. Hewitt (Eds.), Perfectionism: Theory, research, and treatment (pp. 63-88). Washington, DC: American Psychological Association.

Strauss, A., \& Corbin, J. (1998). Basics of qualitative research. Thousand Oaks, CA: Sage. 
Running head: EFFECTIVE TALENT DEVELOPMENT: A COACH'S VIEW

703

704

705

706

707

708

709

710

711

712

713

714

715

716

717

718

719

720

721

722

723

724

Taylor, J.A., \& Shaw, D.F. (2002). The effects of outcome imagery on golf putting performance. Journal of Sports Science, 20, 607-613.

Toering, T.T, Elferink-Gemser, M.T., Jordet, G., \& Visscher, C. (2009). Self-regulation and performance on elite and non-elite youth soccer players. Journal of Sports Sciences, 27(14), 1509-1517.

Toering, T.T., Elferink-Gemser, M.T., Jordet, G., Jorna, C., Pepping, G., \& Visscher, C. (2011). Self-Regulation of Practice Behaviour Among Elite Youth Soccer Players: An exploratory observation study. Journal of Applied Sport Psychology, 23, 110-128.

Vallerand, R.J., Blanchard, C.M., Mageau, G.A., Koestner, R., Ratelle, C.F., Léonard, M., ... Marsolais, J. (2003). Les passions de l'âme: On obsessive and harmonious passion. Journal of Personality and Social Psychology, 85, 756-767.

Vallerand, R. J., Rousseau, F. L., Grouzet, F. M. E., Dumais, A., Grenier, S., \& Blanchard, C. M. (2006). Passion in sport: A look at determinants and affective experiences. Journal of Sport and Exercise Psychology, 28, 454-478.

van Yperen, N. (2009). Why some make it and others do not: Identifying psychosocial factors that predict career success in professional adult soccer. The Sport Psychologist, 23, 317329.

Ward, P., Hodges, N.J., Williams, A.M., \& Starkes, J.L. (2004). Deliberate Practice and expert performance. In: A.M. Williams \& N.J. Hodges (Eds.), Skill Acquisition in Sport: Research, Theory and Practice (pp. 231-258). London: Routledge.

Weiss, W.M., Weiss, M.R. \& Amorose, A.J. (2010). Sport commitment among competitive female athletes: Test of an expanded model. Journal of Sport Sciences, 28(4), 423-434. 
Running head: EFFECTIVE TALENT DEVELOPMENT: A COACH'S VIEW

Zeidner, M. \& Matthews, G. (2007). Evaluation Anxiety. In: A.J. Elliott \& C.S. Dweck (Eds.), Handbook of Competence and Motivation (pp. 141-163). London: Guilford Press.

Zhang, Y.W., Gan, Y.Q., \& Cham, H.N. (2007). Perfectionism, academic burnout and engagement among Chinese college students: A structural equation modelling analysis. Personality and Individual Differences, 43, 1529-1540.

Zimmerman, B.J. (1990). Self-regulated learning and academic achievement: An overview. Educational Psychologist, 25, 3-17.

Zimmerman, B. J. (2006). Development and adaptation of expertise: The role of selfregulatory processes and beliefs. In: K.A. Ericsson, N. Charness, P.J. Feltovich \& R.R. Hoffman (Eds.), The Cambridge Handbook of Expert Performance (pp. 705722). Cambridge: Cambridge University Press.

Zimmerman, B.J., \& Kitstantas, A. (1996). Self-regulated learning of a motoric skill: The role of goal setting and self-monitoring. Journal of Applied Sport Psychology, 8, 69-84.

Zimmerman, B.J., \& Kitstantas, A. (2007). The hidden dimension of personal competence: Self-regulated learning and practice. In: A.J. Elliott \& C.S. Dweck (Eds.), Handbook of Competence and Motivation (pp. 509-526). London: Guilford Press. 
Running head: EFFECTIVE TALENT DEVELOPMENT: A COACH'S VIEW

742 Table 1. Psychological Characteristics Influencing Talent Development

\begin{tabular}{|c|c|c|}
\hline Umbrella Themes & Higher-Order Themes & Sub-Themes \\
\hline \multirow[t]{6}{*}{$\begin{array}{l}\text { Positive Psychological } \\
\text { Characteristics (15) }\end{array}$} & $\begin{array}{l}\text { Cognitive Ability (6) } \\
\text { Competitiveness (8) } \\
\text { Confidence \& Self-Belief (9) } \\
\text { Consistency (9) } \\
\text { Courage (1) } \\
\text { Cultural Identity (5) } \\
\text { Developmental Awareness (10) } \\
\text { Driving Group Standards (2) } \\
\text { Effective Communication (5) } \\
\text { Emotional Intelligence (2) } \\
\text { Flexibility \& Adaptability (2) } \\
\text { Game Understanding (5) } \\
\text { Grit (6) }\end{array}$ & $\begin{array}{l}\text { Passion, Energy \& Enthusiasm (6) } \\
\text { Perseverance (1) }\end{array}$ \\
\hline & Growth Mindset (15) & $\begin{array}{l}\text { Accepting Criticism \& Advice (4) } \\
\text { Accepting Mistakes \& Moving On (3) } \\
\text { Engaging with Challenge (9) } \\
\text { Learning From Mistakes (7) } \\
\text { Reacting Positively to Setbacks (10) }\end{array}$ \\
\hline & $\begin{array}{l}\text { Honesty (2) } \\
\text { Leadership (2) } \\
\text { Manage Transitions Successfully (7) } \\
\text { Maturity (non-physical) (6) }\end{array}$ & \\
\hline & PCDE - Commitment (15) & $\begin{array}{l}\text { Discipline (5) } \\
\text { Doing the Extras (3) } \\
\text { Motivation \& Drive (15) } \\
\text { Positive Work Ethic (12) } \\
\text { Sacrifice (4) }\end{array}$ \\
\hline & $\begin{array}{l}\text { PCDE - Coping with Pressure (6) } \\
\text { PCDE - Focus \& Distraction Control (5) } \\
\text { PCDE - Goal Setting (3) } \\
\text { PCDE - Planning \& Self-Organisation (5) } \\
\text { PDCE - Quality Practice (9) } \\
\text { PCDE - Realistic Performance Evaluation (6) } \\
\text { PCDE - Resilience (7) } \\
\text { PCDE - Self-Awareness (11) } \\
\text { Process Orientated (4) }\end{array}$ & Attention to Detail (7) \\
\hline & Self-Regulation (12) & $\begin{array}{l}\text { Asking Questions (7) } \\
\text { Independence (5) } \\
\text { Ownership of Development (4) } \\
\text { Pro-active (7) }\end{array}$ \\
\hline
\end{tabular}

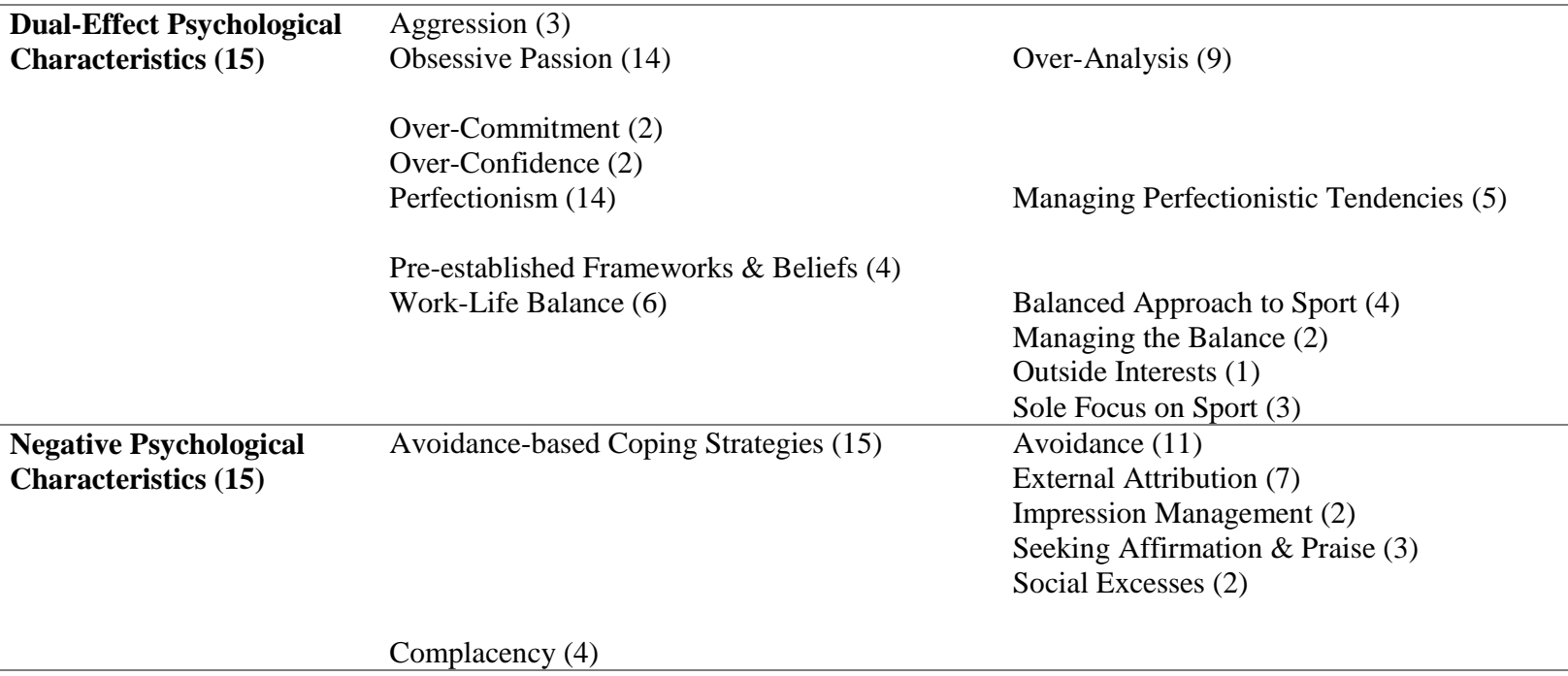


Running head: EFFECTIVE TALENT DEVELOPMENT: A COACH'S VIEW

\section{Disorganised (1) \\ Expectation \& Entitlement (7) \\ Failure to Overcome Challenge (7) \\ Inappropriate Goals (5)}

Lack of Awareness (15)

Lack of Commitment (14)

Loss of Focus / Easily Distracted (5) Mental Health (14)

Negative Attitude (5)

Poor Communicators (1)

Psychological Burnout (3)

Self-Doubt (1)

Self-Handicapping (4)

Shyness (3)
Absence of Challenge (4)

Absence of Coping Mechanisms (7)

Lack of Developmental Awareness (10)

Lack of Self-Awareness (11)

Poor Performance Evaluation (6)

Unrealistic Expectations (2)

Amotivation (7)

Behavioural Incongruence (2)

Doing the Minimum (4)

Inability to Sacrifice (2)

Inconsistency (6)

Depression (8)

Eating Disorders (1)

Prevalence \& Awareness (5)

Suicide or Suicidal Tendencies (2)

743

744 Note. Number in brackets represents number of coaches who identified each

behaviour/characteristic. 